\title{
Effect of Lay-up Placement on Physical Properties of Hybrid Composite Reinforced E-glass/Kevlar 49
}

\author{
Subhan Ali Jogi, ${ }^{1}$, Moazam Baloch², Asif Shah ${ }^{1}$, Zubair Laghari ${ }^{1}$, Inamullah Maitlo ${ }^{1}$, \\ Ifikhar Memon ${ }^{1}$ \\ ${ }^{1}$ Department of Metallurgy and Materials Engineering, Dawood University of Engineering and Technology, Karachi, Pakistan \\ ${ }^{2}$ Department of Metallurgy and Materials Engineering, Mehran University of Engineering and Technology, Jamshoro, Pakistan
}

\section{Email address:}

subhan.duet@gmail.com (S. A. Jogi), balochmoazam@yahoo.com (M. Baloch), asifffshah@hotmail.com (A. Shah),

laghari09mt38.muet@gmail.com (Z. Laghari), engr_maitlo@yahoo.com (I. Maitlo), iftisukkur@yahoo.com (I. Memon)

${ }^{*}$ Corresponding author

\section{To cite this article:}

Subhan Ali Jogi, Moazam Baloch, Asif Shah, Zubair Laghari, Inamullah Maitlo, Ifitkhar Memon. Effect of Lay-up Placement on Physical Properties of Hybrid Composite Reinforced E-glass/Kevlar 49. International Journal of Photochemistry and Photobiology.

Vol. 4, No. 1, 2020, pp. 11-16. doi: 10.11648/j.jpp.20200401.12

Received: April 30, 2019; Accepted: June 23, 2019; Published: January 10, 2020

\begin{abstract}
Hybrid composites have developed and demanding industrial application and replaced metals and non-metal by specific characteristics. The research work concerned with E- glass epoxy and E-glass / Kevlar 49 reinforcement epoxy. The reinforcing materials oriented at $0^{\circ} / 90^{\circ}, 45^{\circ} / 45^{\circ}$ and $30^{\circ} / 60^{\circ}$ lay-up placement. The laminate was produced by hand lay-up method Vacuum Bagging Resin Transfer Molding Technique is used for air escape from the mold cavity for effective adhesion between layers of structural composites. The experimental results achieved by conducting hardness of the samples by following the ASTM standard. The ASTM D-2240 durometer was made to perform hardness over the standard samples. The water absorption characteristics of each specimen of different orientation were observed at different humidity level. Electronic weighing balance ASTM D-570 and Electronic densimeter ASTM D-792 was used for water absorption and density respectively. GFK $-0^{\circ} / 90^{\circ}$ (Glass fiber and Kevlar $0^{\circ} / 90^{\circ}$ ) has good hardness result and low density, GF $0^{\circ} / 90^{\circ}$ has higher density and low water absorption and GFK $30^{\circ} / 60^{\circ}$ has higher capability to absorb water than other orientations, Higher density explain the internal structure with low porous structure which has been confirmed due to low water absorption of this material.
\end{abstract}

Keywords: Hybrid Composites, Hardness, Density, Water Absorption, Glass/Kevlar Fiber Reinforcement, Epoxy, VRTM, Strength-to-Weight

\section{Introduction}

Hybrid composite fabricated by dissimilar reinforcement fibers with strong adhesive materials and has tremendous application in automobile body parts, marine, bulletproof and heat resistance vests for lightweight and specific strength [13]. Kevlar (aramids) is the well known low density, high strength fibers and extensively employed in Aircraft structure, protective shields for body armors and lightweight Sports goods [4-6]. In hybridization synthetic/ natural fiber stacked layer by layer to produce a structure having interlaminar fracture toughness which cannot be achieved by conventional man-made materials. Kevlar/E-glass fibers reinforced epoxy resin has a specific strength and specific stiffness $[7,8]$. The lay-up placement of fibers with advance adhesive thermosetting resin significantly affects the mechanical properties of the hybrid composite. E-glass fibers have better ultimate tensile strength and placed outside layer in lamination to produce a flaw-free structure. For lightweight, high strength reinforcement, the aramid fibers/ glass fibers have a profound achievement to fabricate the laminate. There is no significant difference in density by changing lay-up placement in hybridization [9]. In stacking sequence lamination, the thickness of the sheet is around 3$4 \mathrm{~mm}$ according to ASTM standard. As far as cost competitiveness is concerned the glass fibers are cheaply and easily available in the market with low price whereas Kevlar 
fibers are considerably expensive. For achieving the balance between cost competitiveness and strength to weight ratio of laminate, hybrid composite fabricates by stacking E-glass/ Kevlar fibers. The amount of water absorption in laminate reduces the mechanical strength of the hybrid composite by weakening fiber's strength $[10,11]$ Water absorption characteristics of the laminate have detrimental effects by reducing the mechanical performance of laminate, but it also affects the polymer matrix physically and chemically by attacking fiber-matrix interfaces [12]. The glass fibers reinforced as facings and Kevlar fibers used in core for making sandwiches and commonly used in aerospace and aircraft vehicles. Glass fibers reinforced polymers used in electronic appliances for making printed wire board. Mechanical Behavior of fiber reinforced polymers was investigated by understanding ultimate tensile strength, stiffness, and fiber-matrix bond strength. Use of Kevlar fibers in- plane for lamination and layer thickness enhanced the delamination toughness. Kevlar fibers used the core in lamination sequence to suppress the fracture toughness of the hybrid composite. The aim of the present work is to investigate the physical properties by changing the lay-up placement of hybrid laminate.

\section{Experimental Work}

\subsection{Materials Production Procedure}

The fabrication of laminate and layer formulations were performed at room temperature under pressure 30-100 Psi. Figure 1 shows the fabrication technique by stacking layers of E-glass/Kevlar reinforcement and epoxy resin. The five layers of E-glass fibers and four layers of aramid fibers strongly adhered with an epoxy thermosetting resin. Hybrid laminates of $4 \mathrm{~mm}$ thickness made by vacuum bagging resin transfer molding technique. Epoxy resin and epoxy hardener in the ratio of 5:4 taken for polymerization between thermoplastic and thermosetting. The specimens were prepared for experimental study and oriented at $0^{\circ} / 90^{\circ}$, $45^{\circ} / 45^{\circ}$ and $30^{\circ} / 60^{\circ}$. The sheets of hybrid laminates stayed for curing at room temperature for 24 hours, curing changes thermoplastic liquid in hardened product. Layers formulation and stacking sequence of the hybrid laminate is discussed in Table 1.

\subsection{Hardness Test (Shore-D)}

Hardness is resistant to scratching, indentation and penetration. Albert F. Shore in the 1920s specified the measurement device durometer which is used to analyze the hardness of polymers and polymer matrix composites. The specimens $(2 \mathrm{in} \times 2 \mathrm{in})$ were prepared according to ASTM D2240 standard for the surface hardness of composite material [13-15]. The basic principle for conducting the hardness test is to apply the force without shock and to measure the depth of penetration and indentation. The specimen configuration given in Supplementary Figure 2.

\subsection{Density Test}

Electronic densimeter used to compute the density and specific gravity of sheets, rods and molded parts of polymeric and hybrid composites. Displacement method is employed to determine the density of the composite laminates. For experimental analysis specimens were prepared according to ASTM-792 [16-18] and dimensions were $(70 \mathrm{~mm} \times 15 \mathrm{~mm} \times 4 \mathrm{~mm})$ in figure 2. E-glass / Kevlar fibers reinforced epoxy specimens were weighed in air and then the weight of the laminates was measured after immersing in distilled water at room temperature.

\subsection{Water Absorption Test}

Water absorption in composite structures affects the mechanical and thermal performance when working under different environment. Electronic weighing balance is used to quantify the amount of water absorbed by the material. The specimens were made according to ASTM D-570 $[19,20]$ in Figure 4. The specimens were weighed prior to and after immersion in distilled water at $23^{\circ} \mathrm{C}$ for a day and then weight was considered. The amount of water absorbed is calculated in percentage, water absorption determined by the equation $=\left(\mathrm{w}_{\mathrm{f}}-\mathrm{w}_{\mathrm{i}}\right) / \mathrm{w}_{\mathrm{i}} \times 100$.

\section{Results and Discussions}

\subsection{Hardness}

The effect of fiber content and orientation on the hardness of the hybrid laminates was investigated by conducting a hardness (Shore-D) test. Five specimens of each configuration were considered for experimental observation. Figure 5 shows some minor variation in results obtained from the hardness test. The E-glass/ Kevlar 49 reinforced epoxy resin at $0^{\circ} / 90^{\circ}$ have a slight increment in hardness test results then other orientations.

E-glass reinforced epoxy oriented at $0^{\circ} / 90^{\circ}$ has the same hardness results as GFK $0^{\circ} / 90^{\circ}, 45^{\circ} / 45^{\circ}, 30^{\circ} / 60^{\circ}$. Therefore, results suggest that variation in lay-up placement does not affect the hardness of hybrid composites. The change of fiber content in hybridization for development of hybrid composite laminate makes the difference in hardness.

\subsection{Density Test}

Figure 6 shows the density of laminates at different angles ply orientation $0^{\circ} / 90^{\circ}, 45^{\circ} / 45^{\circ}$, and $30^{\circ} / 60^{\circ}$. The density of various combinations of different lay-up places was also experimentally observed by conducting density test. Strength-to-weight ratio of hybrid composites relies on the selection of fiber for reinforcement. The experimentally conducted results at $0^{\circ} / 90^{\circ}, 45^{\circ} / 45^{\circ}$ and $30^{\circ} / 60^{\circ}$ suggest that change in orientation does not significantly improve the density of the laminate.

The E-glass fibers reinforced epoxy at $0^{\circ} / 90^{\circ}$ has enhanced density, then E-glass/Kevlar reinforced epoxy laminates. Therefore, it can be understood that the density of 
hybrid composite is not affected by lay-up placement, but varies with the amount of fiber reinforcement in the matrix.

\subsection{Water Absorption}

Glass fibers reinforced epoxy at $0^{\circ} / 90^{\circ}$ absorbs fewer amounts of water than Glass/ Kevlar reinforced epoxy at different lay-up placement. The statistical analysis of in Figure 7 shows that E-glass fibers/Kevlar at $30^{\circ} / 60^{\circ}$ has the higher water absorption capacity than $45^{\circ} / 45^{\circ}$ and $0^{\circ} / 90^{\circ}$ orientations. Glass fibers-Kevlar laminate having an angleply $\left(0^{\circ} / 90^{\circ}\right)$ is found to be less water absorbent.

It is to be understood that change in orientation produces a number of vacancies among matrix and interfaces which absorbs the amount of water and reduce the mechanical properties of the hybrid composites. From the results obtained and discussed so far, it can be concluded that the composite which absorbs little or no water possess better mechanical properties Comparison data of hardness, the density of water absorbing GF and GFK shown in figure 8.

Figure 8 Shows the relation of density, water absorption and hardness at the miscellaneous lay-up placement of E-
glass/Kevlar epoxy based hybrid laminated composites. The study of Glass fiber reinforced epoxy at $\left(0^{\circ} / 90^{\circ}\right)$ has minimal water at intake, moderate hardness and an upper limit of density in the graphical representation. The measured hardness and amount of water absorption strongly rely upon the collection of suitable fiber and lay-up position in the matrix phase. GF epoxy and glass/ Kevlar hybrid laminates at ply $\left(0^{\circ} / 90^{\circ}\right)$ have minimum water absorption and have a suitable candidate for specific strength. The physical performance in service the lay-up placement $\left(45^{\circ} / 45^{\circ}\right)$ and $\left(30^{\circ} / 60^{\circ}\right)$ has to suppress water absorption then $\left(0^{\circ} / 90^{\circ}\right)$ ply. The density and hardness are not strongly affected by changing lay-up placement but affected by replacing the position of fiber in resin.

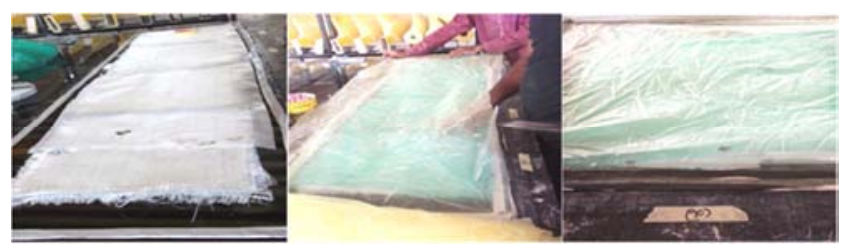

Figure 1. VRTM Technique while Peel ply placement, Bagging with sealing tape and Resin Transfer process.



(a)

(b)

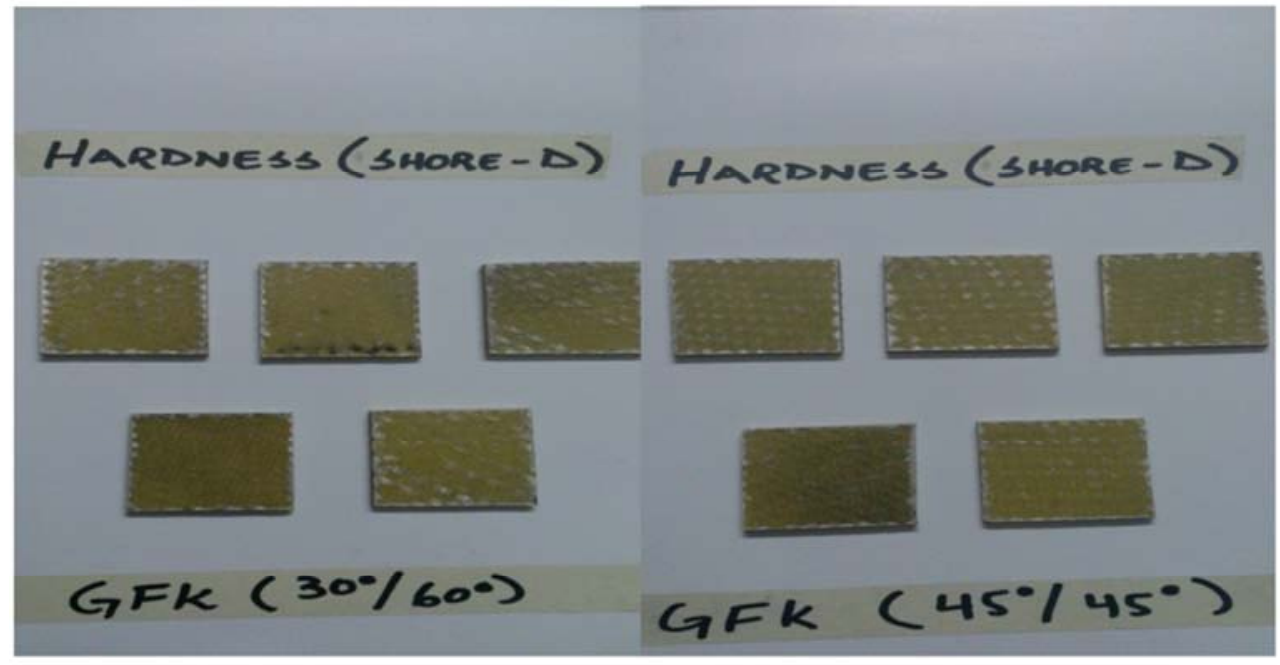

(c)

(d)

Figure 2. Hardness test specimens (a) GF $0^{\circ} / 90^{\circ}$ (b) $G F K 0^{\circ} / 90^{\circ}$ (c) $G F K 30^{\circ} / 60^{\circ}$ (d) GFK $45^{\circ} / 45^{\circ}$. 




(a)

(b)

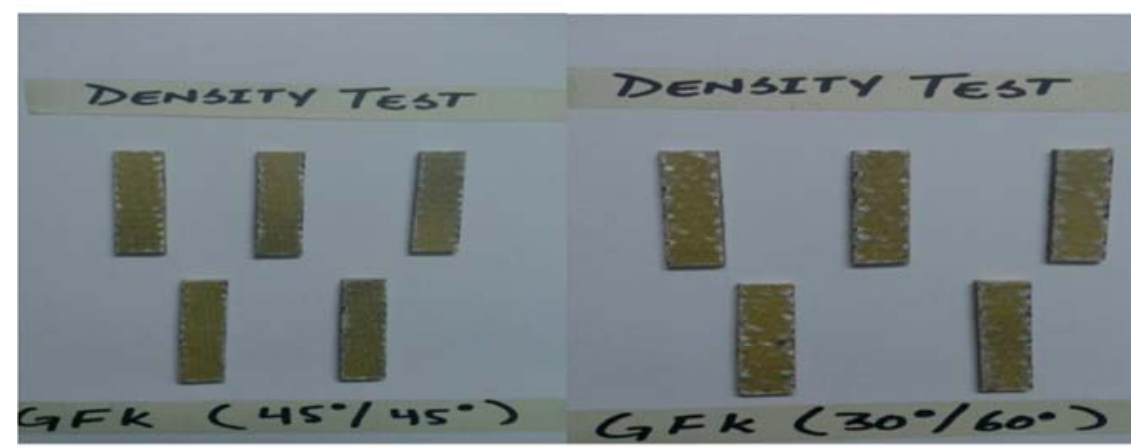

(c)

(d)

Figure 3. Specimens for density test (a) E-glass fibers reinforced epoxy at $0^{\circ} / 90^{\circ}$ (b) E-glass/Kevlar epoxy at $0^{\circ} / 90^{\circ}$ (c) E-glass/Kevlar epoxy at $45^{\circ} / 45^{\circ}$ (d) Eglass/Kevlar reinforced epoxy at $30^{\circ} / 60^{\circ}$.

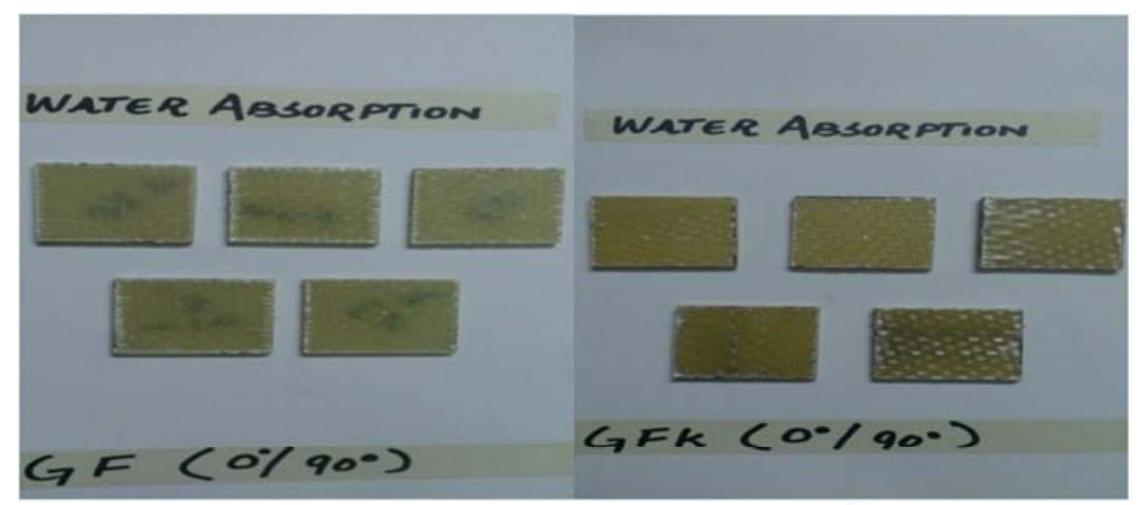

(a)

(b)

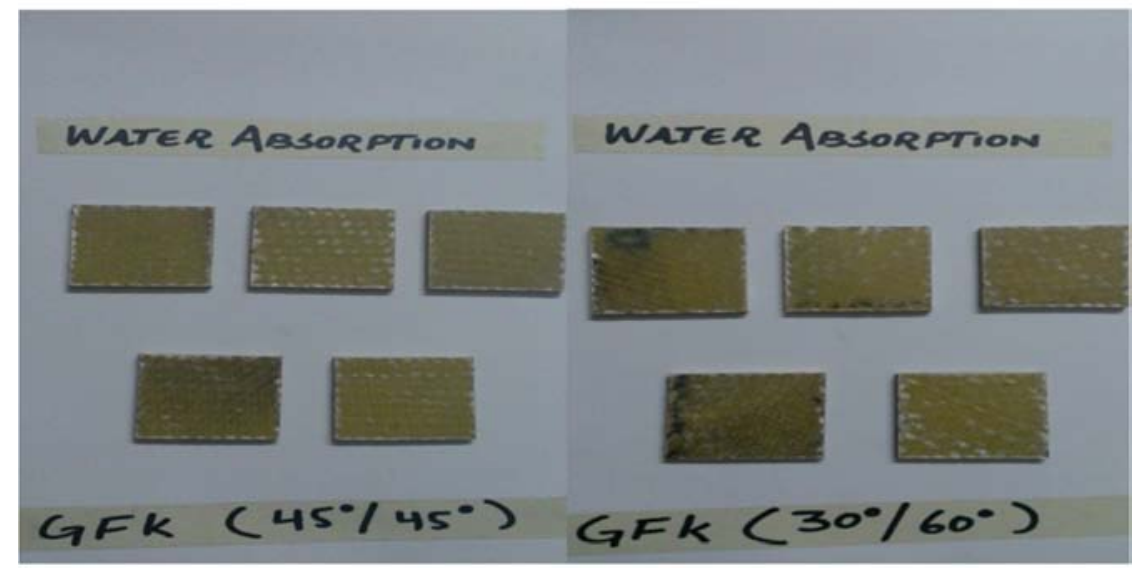

(c)

(d)

Figure 4. Shows laminates at different layup placement for water absorption test (a) Glass fibers epoxy at $0^{\circ} / 90^{\circ}$ (b) E-glass $/$ Kevlar epoxy at $0^{\circ} / 90^{\circ}$ (c) GFK $45^{\circ} / 45^{\circ}\left(\right.$ d) $G F K 30^{\circ} / 60^{\circ}$ 


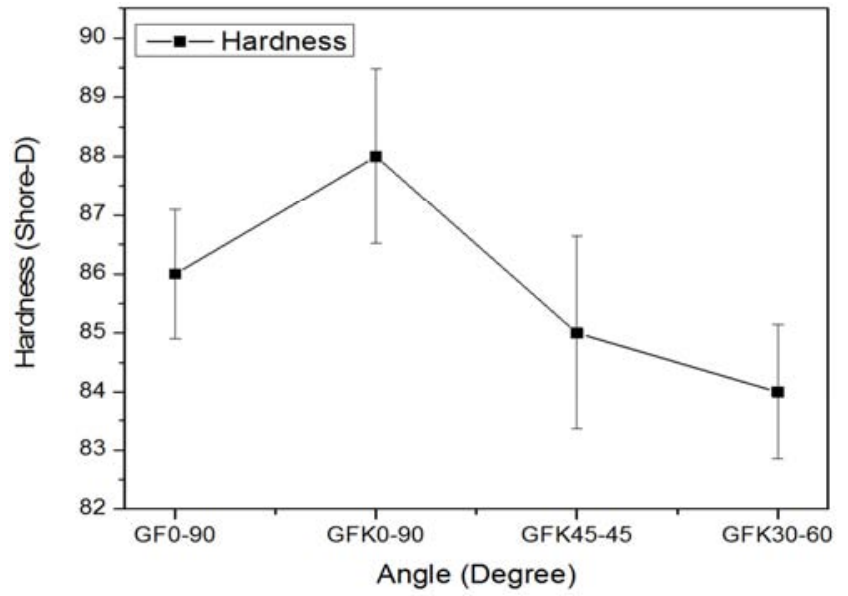

Figure 5. Hardness test results showing the standard deviation of GF, GFK at different lay-up places.

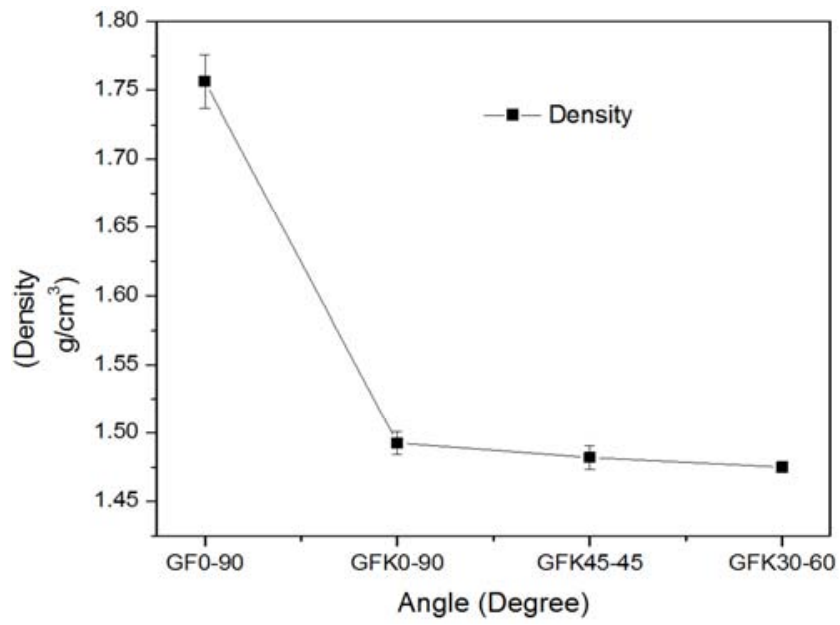

Figure 6. Density with standard deviation of GF and GFK at different lay-up placement.

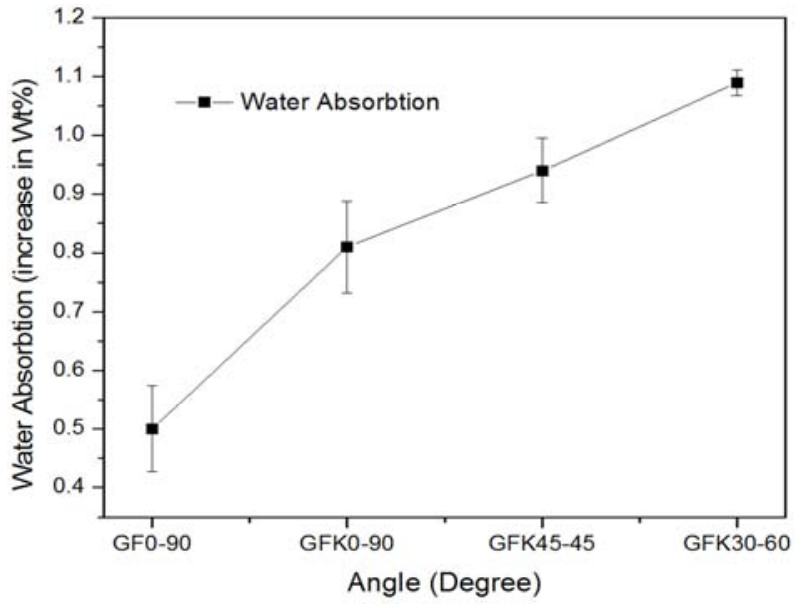

Figure 7. Water absorption showing the standard deviation of GF and GFK at different lay-up placemen.

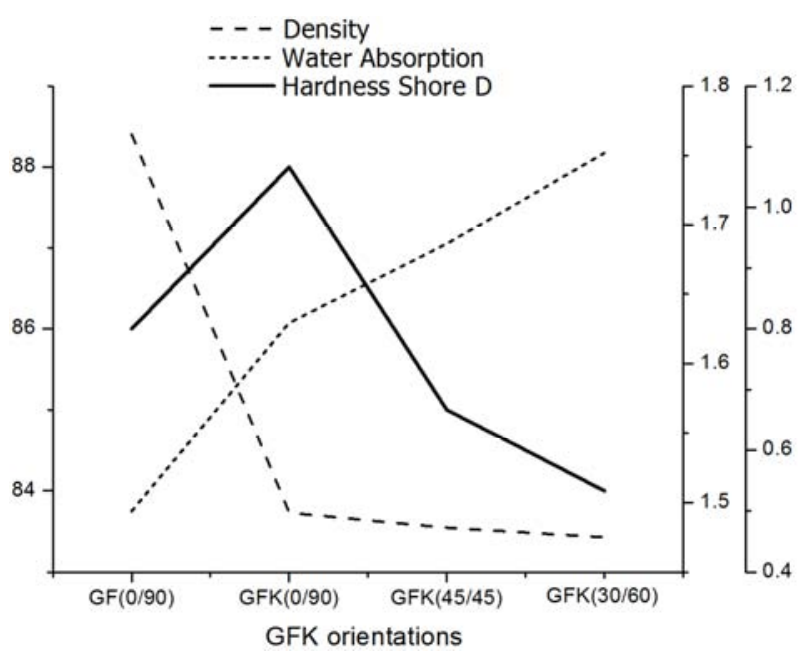

Figure 8. Comparison graph of hardness, density, water absorption at $0 \% 90^{\circ}, 45^{\circ} \% 5^{\circ}, 30^{\circ} \% 0^{\circ}$ lay-up placement.

Table 1. Layer formulations at $0^{\circ} / 90^{\circ}, 45^{\circ} / 45^{\circ}$ and $30^{\circ} / 60^{\circ}$.

\begin{tabular}{llllll}
\hline Layers formation & Layers & $\begin{array}{l}\text { Layers of Glass fiber } \\
\text { (Roving) }\end{array}$ & $\begin{array}{l}\text { Layers of Kevlar } \\
\text { fibers 49 }\end{array}$ & $\begin{array}{l}\text { Angle of orientation } \\
\text { G. F }\end{array}$ & $\begin{array}{l}\text { Angle of orientation } \\
\text { of K. F }\end{array}$ \\
\hline A & 09 & 09 & - & $\left(0^{\circ} / 90^{\circ}\right)$ & - \\
B & 09 & 05 & 04 & $0^{\circ}$ & $90^{\circ}$ \\
C & 09 & 05 & 04 & $30^{\circ}$ & $60^{\circ}$ \\
D & 09 & 05 & 04 & $45^{\circ}$ & $45^{\circ}$ \\
\hline
\end{tabular}

\section{Conclusion}

From the experimental evaluation of lamination, it is concluded that the change in lay-up placement make changes in mechanical and physical properties of the hybrid composites.

This is during the variation in the internal design of reenforcement placement, the spaces and conjunction of fibers changes in the mechanical and physical properties of material, Glass/Kevlar hybrid composite at $0^{\circ} / 90^{\circ}$ orientation has minimum water absorption and higher density which is due to higher volume covered by re-enforcement and make it unable to absorb more amount of water with higher hardness as compared to other orientations. Therefore, it is also under the conclusion that the best orientation can be used is $0^{\circ} / 90^{\circ}$. The recommendation can also be made that at $0^{\circ} / 90^{\circ}$ lay-up placement has anisotropic in multiple directions except $90^{\circ}$ and $180^{\circ}$ of fiber's lay-up, in this conclusion such properties barrier material is best suited for aerospace and marine applications.

\section{References}

[1] Jefferson, A. J., V. Arumugam, and H. Dhakal, Repair of Polymer Composites: Methodology, Techniques, and Challenges. 2018: Woodhead Publishing. 
[2] Kalaiyarasan, A., P. Ramesh, and P. Paramasivam, Study of Advanced Composite Materials in Aerospace Application. International Journal Of Scientific Research In Mechanical And Materials Engineering, 2016. 1 (1): p. 25-34.

[3] Quan, Y. M. and L. H. Sun. Investigation on drilling-induced delamination of CFRP with infiltration method. in Advanced Materials Research. 2010. Trans Tech Publ.

[4] Sockalingam, S., et al., Transverse compression behavior of Kevlar KM2 single fiber. Composites Part A: Applied Science and Manufacturing, 2016. 81: p. 271-281.

[5] Nithya, S., et al., Investigation of Stacking Sequence on Glass and Kevlar Fiber. Journal of Chemical and Pharmaceutical Sciences ISSN, 2017. 974: p. 2115.

[6] Luise, R. R., Applications of High Temperature Polymers: 0. 2018: CRC Press.

[7] Andrew, J. J., et al., Quasi-static indentation properties of damaged glass/epoxy composite laminates repaired by the application of intra-ply hybrid patches. Polymer Testing, 2017. 61: p. 132-145.

[8] Saba, N., et al., A review on dynamic mechanical properties of natural fibre reinforced polymer composites. Construction and Building Materials, 2016. 106: p. 149-159.

[9] Agarwal, B. D., L. J. Broutman, and K. Chandrashekhara, Analysis and performance of fiber composites. 2017: John Wiley \& Sons.

[10] Reis, P., M. Neto, and A. Amaro, Effect of the extreme conditions on the tensile impact strength of GFRP composites. Composite Structures, 2018. 188: p. 48-54.

[11] MUSTAFA, E. H. B., et al., Manufacturing Technology of Composite Material Structure. 2017, Sudan University of Science and Technology.

[12] Kanaginahal, G. M. and M. Murthy, Microstructural Study and Evaluation of Few Mechanical Properties of Hybrid Composites. Advanced Materials Manufacturing \& Characterization, 2017. 7 (1).

[13] Zhao, H., D. Allanson, and X. Ren, Use of shore hardness tests for in-process properties estimation/monitoring of silicone rubbers. Journal of Materials Science and Chemical Engineering, 2015. 3 (07): p. 142.

[14] Broitman, E., Indentation hardness measurements at macro-, micro-, and nanoscale: a critical overview. Tribology Letters, 2017. 65 (1): p. 23

[15] Tobaruela, A., et al., Indentation hardness: A simple test that correlates with the dissipated-energy predictor for fatigue-life in bovine pericardium membranes for bioprosthetic heart valves. journal of the mechanical behavior of biomedical materials, 2016. 61: p. 55-61.

[16] Lu, N., R. H. Swan Jr, and I. Ferguson, Composition, structure, and mechanical properties of hemp fiber reinforced composite with recycled high-density polyethylene matrix. Journal of Composite Materials, 2012. 46 (16): p. 1915-1924.

[17] Shivamurthy, B., et al., Mechanical properties and sliding wear behavior of jatropha seed cake wastelepoxy composites. Journal of Material Cycles and Waste Management, 2015. 17 (1): p. 144-156.

[18] Coltro, L., J. B. Pitta, and E. Madaleno, Performance evaluation of new plasticizers for stretch PVC films. Polymer Testing, 2013. 32 (2): p. 272-278.

[19] Shah, A. and S. Lakkad, Mechanical properties of jutereinforced plastics. Fibre Science and Technology, 1981. 15 (1): p. 41-46.

[20] Haque, M. M., et al., Physico-mechanical properties of chemically treated palm and coir fiber reinforced polypropylene composites. Bioresource technology, 2009. 100 (20): p. 4903-4906. 